\title{
The role of selenium in bevacizumab induced cardiotoxicity
}

\author{
Oncel CR ${ }^{1}$, Ovey IS ${ }^{2}$ \\ Department of Cardiology, Alanya Alaaddin Keykubat University, School of Medicine, Alanya, Antalya, Turkey. \\ can.oncel@alanya.edu.tr
}

\section{ABSTRACT}

OBJECTIVE: We investigated the role of selenium in bevacizumab induced cardiotoxicity and involvement of transient receptor potential vanilloid 1 (TRPV1) channels in cardiomyocytes.

MATERIALS AND METHODS: All cells (Human cardiomyocyte cell line) were cultured at $37^{\circ} \mathrm{C}$. We divided the cells into seven groups as control, bevacizumab, bevacizumab + capsazepin, bevacizumab + selenium, bevacizumab + selenium + capsazepin, selenium and selenium + capsazepin groups. Cells in the groups were stimulated with capsaicin and inhibited with capsazepin in related experiments for activation and inactivation of TRPV1 channels, respectively.

RESULTS: Cytosolic calcium, apoptosis and intracellular ROS production levels were lower in bevacizumab + selenium group than in the bevacizumab group of cardiomyocytes $(p<0.001)$. Also, values were markedly lower in the bevacizumab + selenium + capsazepine group when compared to the bevacizumab + selenium group $(p<0.001)$.

CONCLUSION: We found that cytosolic calcium, apoptosis, intracellular ROS production levels were increased in bevacizumab induced cardiotoxicity and selenium treatment could have beneficial effects on these parameters (Fig. 5, Ref. 51). Text in PDF www.elis.sk.

KEY WORDS: apoptosis, bevacizumab, cardiomyocyte, transient receptor potential vanilloid 1, selenium.

\section{Introduction}

Calcium has an essential role in cellular homeostasis and survival by assuming important functions in intra and extracellular signaling pathways (1). Also, it has been shown that calcium is involved in cell proliferation, apoptosis and oxidative stress (2). Different factors such as: drugs and disease states are associated with $\mathrm{Ca}^{2+}$ influx and oxidative stress. Increased calcium levels stimulate reactive oxygen species (ROS). Increased ROS and calcium load lead to opening of protein complex in the inner mitochondrial membrane and releasing of proapoptotic factors, which cause apoptosis (3). Interactions among ROS and $\mathrm{Ca}^{2+}$ levels are bidirectional, whereas an excessive ROS production causes $\mathrm{Ca}^{2+}$ channel opening and increases intracellular calcium levels (4). There are different $\mathrm{Ca}^{2+}$ transport processes in myocardial cells. One of the membrane transporters that is localized in the plasma membrane and responsible for calcium ion transport is a transient receptor potential (TRP) $(5,6)$. It has been demonstrated that TRP vanilloid 1 (TRPV1) channels are found in the ventricles of heart in the cardiovascular system (7). TRPV1 channel, a member of vanilloid TRP

${ }^{1}$ Department of Cardiology, Alanya Alaaddin Keykubat University, School of Medicine, Alanya, Antalya, and ${ }^{2}$ Department of Physiology, Alanya Alaaddin Keykubat University, School of Medicine, Alanya, Antalya, Turkey

Address for correspondence: C.R. Oncel, Alanya Alaaddin Keykubat University, School of Medicine, Department of Cardiology, Konya Cimento Street No: 80, Alanya, Antalya, Turkey. Zip Code: 07450

Phone: +905063715199 family, is one of the calcium permeable cation channel, which has a critical role in cardiovascular diseases such as: atherosclerosis, hypertension and heart failure (8-10). Congestive heart failure is also associated with a deterioration of calcium balance and increased cytokine production as well as free oxygen radicals $(11,12)$. Cardiomyocytes are one of the main targets of ROS. Involvement of $\mathrm{Ca}^{2+}$ entry and oxidative injury through TRPV1 channel modulation in apoptosis was demonstrated in previous studies $(13,14)$. We observed that $\mathrm{Ca}^{2+}$ entry was increased with capsaicin administration due to TRPV1 activation in a pre-study of cardiomyocytes.

Chemotherapy is a common treatment for several types of cancer, but chemotherapy induced cardiotoxicity is a serious, life threatening complication, which limits the clinical use of chemotherapeutic agents. One of the most widely accepted pathophysiological mechanism underlying chemotherapy induced cardiotoxicity is a generation of oxidative stress (15). Bevacizumab is an antiangiogenic chemotherapeutic and targets vascular endothelial growth factor (VEGF). It is used in several malignancies, including metastatic breast cancer (16). Congestive heart failure associated with bevacizumab has been reported as serious adverse event in cancer patients (17). Although an important role of VEGF pathway in heart failure has been demonstrated before, underlying pathophysiological mechanism associated with bevacizumab induced cardiomyopathy is not well understood. In the recent study by Yazici et al., it has been shown that bevacizumab could induce apoptosis and mitochondrial oxidative stress in human osteoblast like cell line through TRPV1 channel activation (18). So, we decided to evaluate the effect of bevacizumab therapy in cardiomyo- 
cytes. As the management of cardiovascular events in patients treated with bevacizumab is not well defined; it is very important to understand the molecular mechanism of chemotherapy induced cardiotoxicity. The mechanisms producing toxicity are not yet completely defined. Although no reliable and effective preventive treatment is available, we decided to investigate whether antioxidants could show protective effects in cardiotoxicity.

In this study, we wanted to evaluate the effect of bevacizumab on calcium signaling, apoptosis and oxidative stress in cardiomyocytes and we wanted to investigate the modulator role of selenium (as an important cardioprotective antioxidant) in bevacizumab induced cardiotoxicity (19).

\section{Materials and methods}

\section{Cell culture and reagents}

AC16 (Human cardiomyocyte cells) was obtained from ATCC. Dulbecco's modified Eagle's medium (DMEM) (Sigma) was used for cardiomyocytes culture, containing $10 \%$ fetal bovine serum (FBS) (Fisher Scientific, and $1 \%$ penicillin/streptomycin (ThermoFischer). Cardiomyocyte cells were evenly distributed as $1 \times 10^{6}$ cells in each of 8-10 flasks (filter cap, sterile, $5 \mathrm{ml}, 25 \mathrm{~cm}^{2}$ ). A humidified incubator was used to incubate cardiomyocytes at $37^{\circ} \mathrm{C}$ at $5 \% \mathrm{CO}_{2}$. After the cells have reached $75-85 \%$ confluence, they were incubated with the chemical compounds described in the groups section. The cells were examined daily for the evidence of contamination. After treatments, the cells were detached with $0.25 \%$ Trypsin-EDTA for analysis and split into the sterile falcon tubes for analyses.

Cell viability (MTT) dye was purchased from Thermo Fischer (Massachusetts, USA). Dihydrorhodamine-123 (DHR123) obtained from Molecular Probes (OR, USA). Caspase 3 and Caspase 9 substrates were obtained from Biovision (San Francisco, USA). APOPercentage dyes with releasing buffer were obtained from Biocolor Ltd. (Northern Ireland), JC1 was purchased from Santa Cruz (Texas, USA), Fura 2 AM was purchased from Calbiochem (Darmstadt, Germany).

The study was planned as the 7 main groups below:

Group 1 (Control): None of the study drugs were used and cardiomyocytes were preserved in a flask with the same cell culture condition.

Group 2 (BVC): Cardiomyocytes in the group were incubated with 1 microgram $(\mu \mathrm{g})$ bevacizumab for $24 \mathrm{hrs}$.

Group 3 (BVC+CAPZ): Cardiomyocytes in the group were incubated with $1 \mu \mathrm{g}$ bevacizumab for $24 \mathrm{hrs}$ and then incubated with capsazepin (CAPZ, $0.1 \mathrm{mM}, 30 \mathrm{~min}$ ).

Group $4(B V C+S e)$ : Cardiomyocytes in the group were incubated with $1 \mu \mathrm{g}$ bevacizumab for $24 \mathrm{hrs}$ and then incubated with $1 \mu \mathrm{M}$ selenium for $24 \mathrm{hrs}$.

Group $5(B V C+S e+C A P Z)$ : Cardiomyocytes in the group were incubated with $1 \mu \mathrm{g}$ bevacizumab for $24 \mathrm{hrs}$ and then incubated with $1 \mu \mathrm{M}$ selenium for $24 \mathrm{hrs}$ and then incubated with capsazepin (CAPZ, $0.1 \mathrm{mM}, 30 \mathrm{~min}$ ).

Group 6 (Se): Cardiomyocytes in the group were incubated with $1 \mu \mathrm{M}$ selenium for $24 \mathrm{hrs}$.
Group 7 (Se+CAPZ): Cardiomyocytes in the group were incubated with $1 \mu \mathrm{M}$ selenium for $24 \mathrm{hrs}$ and then incubated with capsazepin (CAPZ, $0.1 \mathrm{mM}, 30 \mathrm{~min}$ ).

In CAPZ incubated groups, cardiomyocyte cells were also blocked by TRPV1 blocker CAPZ $(0.1 \mathrm{mM}, 30 \mathrm{~min})$ before a related analysis in the existence of $1.2 \mathrm{mM}$ calcium in extracellular environment. For all experiments (except for calcium signaling), the cells were further treated with capsaicin (CPSN, 0.1 mM, 10 min) for activation of TRPV1 channel before a related analysis. During calcium signaling analysis (Fura-2/AM), the cells were stimulated on 20th cycles with $0.1 \mathrm{mM} \mathrm{CPSN}$ in the existence of $1.2 \mathrm{mM}$ calcium in extracellular environment.

\section{Measurements of intracellular calcium concentration}

UV light excitable Fura 2 AM (acetoxymethyl ester) dye was used for measuring intracellular calcium level in cardiomyocytes. The relevant experiments were done on the strength of the experimental procedure of Uguz et al, which included $4 \mu \mathrm{M}$ Fura $2 \mathrm{AM}$ florescent dye to dye staining period ending (20). Fluorescence emission intensity at $510 \mathrm{~nm}$ was determined in individual wells using a plate reader equipped with an automated injection system (SynergyTM H1, Biotek, USA) at alternating excitation wavelengths of 340 and $380 \mathrm{~nm}$ every $3 \mathrm{~s}$ for 50 acquisition cycles (cycle: 3 s; exposure: 25 flashes; gain: 120). During the measurement of intracellular calcium signaling, TRPV1 channels were stimulated by automatic injector with Capsaicin $(0.1 \mathrm{mM})$ on 20th cycle. Measurement of $\mathrm{Ca}^{2+}$ analysis was performed as modified by Uguz et al, and Martinez et al, in previous studies (20, 21).

\section{Intracellular ROS production measurement}

Dihydrorhodamine 123 (DHR 123) is a non-charged and nonfluorescent dye, which easily go through the cell membrane. Inside the cardiomyocyte cell, DHR123 is oxidized to cationic rhodamine 123 (Rh 123), which is localized in the mitochondria and demonstrates green fluorescence. The cells $\left(10^{6}\right.$ cells $/ \mathrm{ml}$ for per group $)$ were incubated with $20 \mu \mathrm{m}$ DHR 123 as florescent oxidant dye at $37^{\circ} \mathrm{C}$ for $25 \mathrm{~min}$ (22). Synergy ${ }^{\mathrm{TM}} \mathrm{H} 1$ automatic microplate reader device was used for determining Rh 123 fluorescent intensities. The analyzes were performed at $488 \mathrm{~nm}$ (excitation) and $543 \mathrm{~nm}$ (emission) wavelengths. We presented the data as fold increase over the level before treatment.

\section{Apoptosis assay}

The APOPercentage ${ }^{\mathrm{TM}}$ cell apoptosis assay was used for the detection and quantification of apoptosis. The APOPercentage dye is actively bound to phosphatidyl-serine lipids and transferred into the cells and apoptotic cells are stained red. The apoptosis analyzes procedure was performed according to the manufacturer instruction and Özdemir et al (23). The cardiomyocyte cells were analyzed for apoptotic cells detection by spectrophotometry (multiplate reader) at $550 \mathrm{~nm}$ (Synergy ${ }^{\mathrm{TM}} \mathrm{H1}$, Biotek, USA).

\section{Caspase 3-9 activity assays}

Caspase 9 and Caspase 3 activity evaluation methods were based on as previously reported $(24,25)$. Caspase 9 (AC-LEHD- 
AMC) and Caspase 3 (ACDEVD-AMC) substrates cleavages were calculated with Synergy ${ }^{\mathrm{TM}}$ H1 microplate reader (Biotek, USA) with $360 \mathrm{~nm}$ and $460 \mathrm{~nm}$ wavelengths (excitation/emission). The values were evaluated as fluorescent units/mg protein and shown as fold change from the level before treatment (experimental/control).

\section{Mitochondrial membrane potential (JC-1) analyses.}

JC1 $(1 \mu \mathrm{M})$, which is a mitochondrial membrane potential fluorescence dye intensity, was evaluated by $485 \mathrm{~nm}$ (green) excitation wavelength and the emission wavelength of $535 \mathrm{~nm}$, the red signal at the $540 \mathrm{~nm}$ (excitation) and $590 \mathrm{~nm}$ (emission) the wavelengths (Synergy ${ }^{\mathrm{TM}} \mathrm{H} 1$, Biotek, USA) $(26,27)$. Data are presented as the emission ratios (590/535). Mitochondrial membrane potential changes were quantified as the integral of the decrease in JC1 fluorescence ratio of experimental/control.

\section{Cell viability (MTT) assay}

Cell viability was evaluated with MTT (3-(4,5-dimethylthiazol-2-yl)-2,5-diphenyltetrazolium bromide) assay. After treatments with chemical compounds as described in the group sections, first the cardiomyocytes were washed and then incubated with fresh DMEM containing MTT $(0.5 \mathrm{mg} / \mathrm{ml})$ at $37{ }^{\circ} \mathrm{C}$ for $90 \mathrm{~min}(28)$. Then, the supernatants were removed and Dimethyl-sulfoxide was added to dissolve the formazan crystals. Optical density was estimated by Synergy ${ }^{\mathrm{TM}} \mathrm{H} 1$ automatic microplate reader device (Biotek, USA) at a test wavelength of $490 \mathrm{~nm}$ and a reference wavelength of $650 \mathrm{~nm}$ to nullify the effect of cell debris. The ob-

a

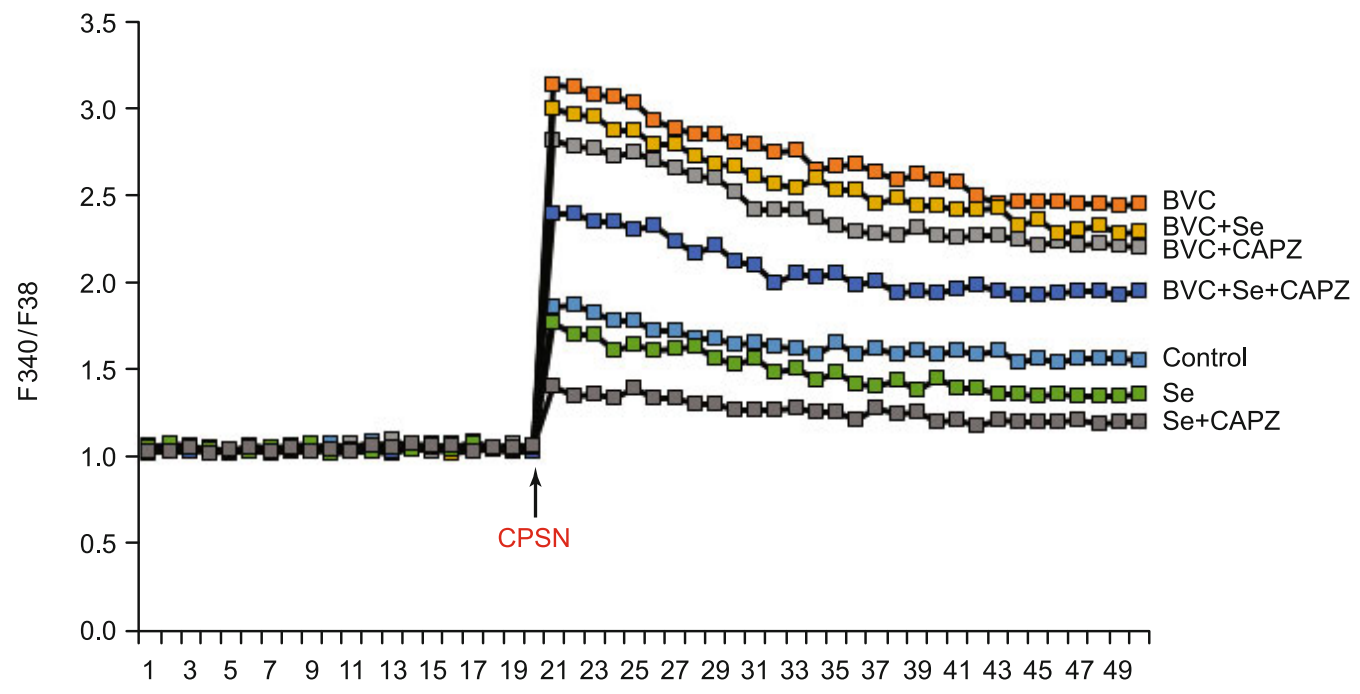

Cycle number

(b)

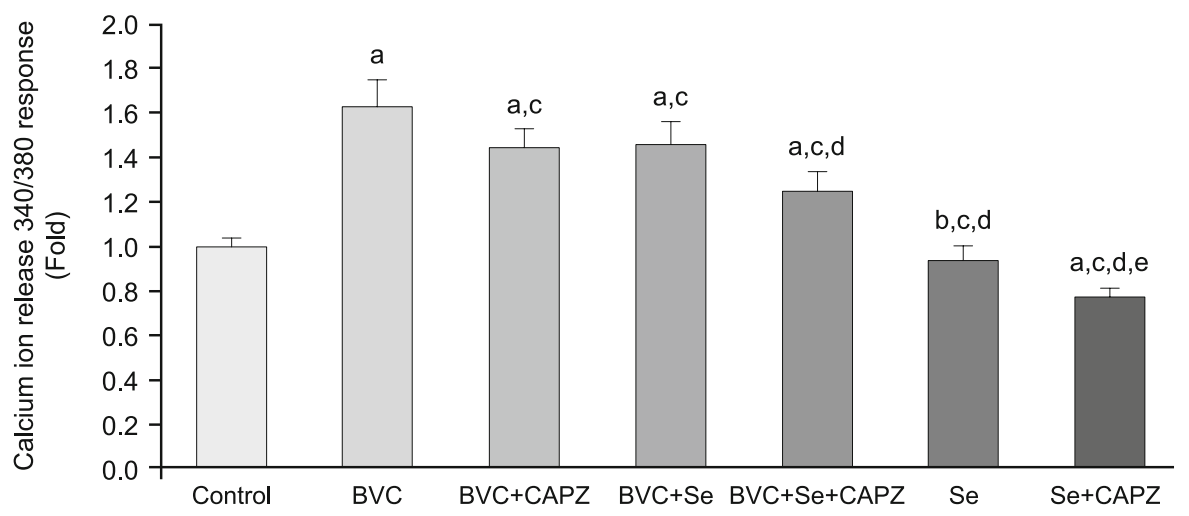

Fig. 1a, b. The effect of bevacizumab (1 microgram, $24 \mathrm{hrs})$ and selenium $(1 \mu \mathrm{M}, 24 \mathrm{hrs})$ on cytosolic calcium levels in cardiomyocyte cells. The cells were stimulated by capsaicin (CPSN $0.1 \mathrm{mM}$ and on $20^{\text {th }}$ cycle) and the cells in the capsazepine groups were inhibited by capsazepine (CAPZ $0.1 \mathrm{mM}$ for $30 \mathrm{~min}$ ) (mean $\pm \mathrm{SD}$ and $\mathrm{n}=10$ )). ${ }^{\mathrm{a}} \mathbf{p}<0.001$ and ${ }^{\mathrm{b}} \mathrm{p}<0.05$ vs control, ${ }^{\mathrm{c}} \mathrm{p}<0.001$ vs $\mathrm{BVC}$ group, ${ }^{\mathrm{d}} \mathbf{p}<0.001 \mathrm{vs} \mathrm{BVC}+\mathrm{Se}$ group and ${ }^{\mathrm{e}} \mathbf{p}<\mathbf{0 . 0 5}$ vs Se group. BVC: Bevacizumab group, BVC+CAPZ: Bevacizumab + capsazepine group, BVC+Se: Bevacizumab + Selenium group, BVC+Se+CAPZ: Bevacizumab + Selenium + capsazepine group, Se: Selenium group, Se+CAPZ: Selenium + capsazepine group. 


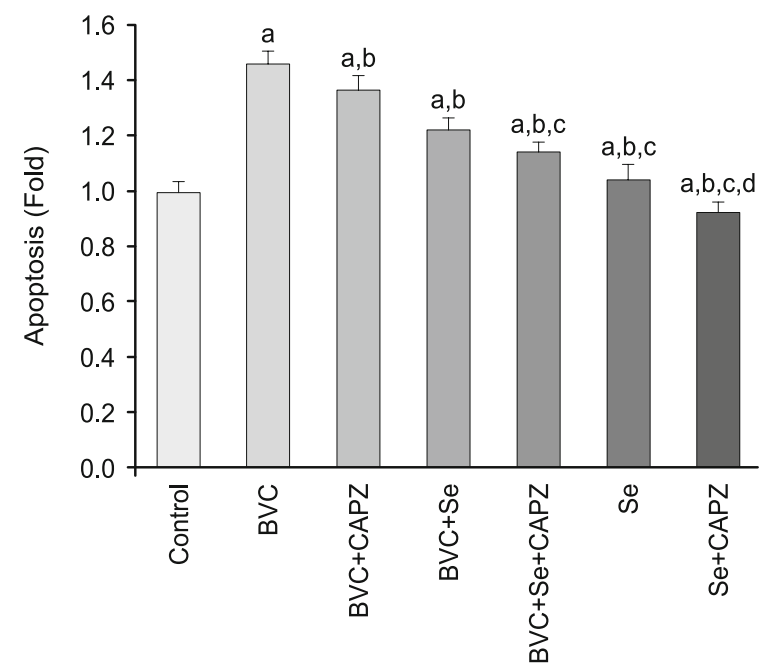

Fig. 2. The effect of bevacizumab (1 microgram, $24 \mathrm{hrs}$ ) and selenium $(1 \mu \mathrm{M}, 24 \mathrm{hrs})$ on apoptosis levels in the cardiomyocytes. The cells were stimulated by capsaicin (CPSN $0.1 \mathrm{mM}$ for $10 \mathrm{~min}$ ) and the cells in the capsazepine groups were inhibited by capsazepine (CAPZ $0.1 \mathrm{mM}$ for 30 min). (mean \pm SD and $n=10$ ). ${ }^{a} p<0.001$ vs control, ${ }^{b} p<0.001$ vs BVC group, ${ }^{\mathrm{c}} \mathbf{p}<\mathbf{0 . 0 0 1} \mathrm{vs} \mathrm{BVC}+$ Se group and ${ }^{\mathrm{d}} \mathrm{p}<\mathbf{0 . 0 0 1} \mathrm{vs}$ Se group. BVC: Bevacizumab group, BVC+CAPZ: Bevacizumab + capsazepine group, BVC+Se: Bevacizumab + Selenium group, BVC+Se+CAPZ: Bevacizumab + Selenium + capsazepine group, Se: Selenium group, Se+CAPZ: Selenium + capsazepine group.

tained data are showed as fold change from the level before treatment (experimental/control).

\section{Statistical analyses}

The values are presented as the mean \pm standard deviation (SD). Statistical significance between the groups was calculated by one-way analysis of variance (ANOVA) and Mann-Whitney U test. All the data were analyzed by SPSS statistical program (version 9.05 software, SPSS Inc. Chicago, Illinois, USA) $\mathrm{p}<0.05$ was considered significant.

\section{Results}

Effects of bevacizumab and selenium on cytosolic calcium levels in cardiomyocytes

The effect of bevacizumab and selenium administrations on cytosolic calcium levels in cardiomyocyte cells are shown in Figure 1a,b. The TRPV1 channel blocker capsazepine was used to evaluate intracellular calcium increase through TRPV1 channels in bevacizumab toxicity model of cardiomyocytes. As shown in Figure $1 \mathrm{~b}$, the $\mathrm{Ca}^{2+}$ concentration in cardiomyocytes was $(\mathrm{p}<$ $0.001)$ greater in the bevacizumab group than in the control. The $\mathrm{Ca}^{2+}$ level was lower in the selenium and the selenium + capsazepine groups compared to the control $(\mathrm{p}<0.05 ; \mathrm{p}<0.001$ respectively). Also cytosolic $\mathrm{Ca}^{2+}$ level was significantly lower in the bevacizumab + capsazepine, bevacizumab + selenium and bevacizumab + selenium + capsazepine group than in the bevacizumab group $(\mathrm{p}<0.001)$.
In addition, cytosolic $\mathrm{Ca}^{2+}$ concentration in the cardiomyocytes was markedly lower in the bevacizumab + selenium + capsazepine group compared to the bevacizumab + selenium group $(\mathrm{p}<0.001)$.

Effects of bevacizumab and selenium on apoptosis levels in cardiomyocytes

Effects of bevacizumab and selenium administrations on apoptosis levels are shown in Figure 2. The apoptosis values were greater in the bevacizumab group than in the control group. The apoptosis values were lower in the selenium and the bevacizumab + selenium group than in the bevacizumab group of cardiomyocytes $(\mathrm{p}<0.001)$. Also, the values were lower in the bevacizumab + selenium + capsazepine group when compared with the bevacizumab + selenium group of cardiomyocytes $(p<0.001)$

Effects of bevacizumab and selenium on intracellular ROS production in cardiomyocytes

Intracellular ROS production of the groups are shown in Figure 3. The ROS production values of the bevacizumab group were greater than the values of the control group. The values were significantly lower in the bevacizumab + capsazepine $(\mathrm{p}<0.001)$, the bevacizumab + selenium $(\mathrm{p}<0.001)$ and the bevacizumab + selenium + capsazepine $(\mathrm{p}<0.001)$ groups than in the bevacizumab group. Also, the ROS production was markedly lower in the bevacizumab + selenium + capsazepine group, when compared to the bevacizumab + selenium group $(\mathrm{p}<0.001)$.

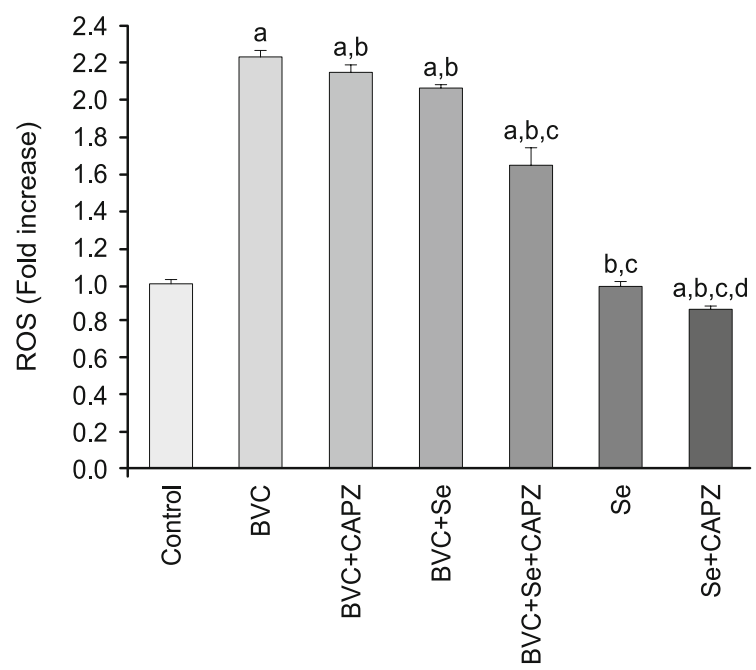

Fig. 3. The effect of bevacizumab (1 microgram, $24 \mathrm{hrs)} \mathrm{and} \mathrm{selenium}$ $(1 \mu \mathrm{M}, 24 \mathrm{hrs})$ on reactive oxygene species levels in the cardiomyocytes. The cells were stimulated by capsaicin (CPSN $0.1 \mathrm{mM}$ for $10 \mathrm{~min}$ ) and the cells in the capsazepine groups were inhibited by capsazepine (CAPZ $0.1 \mathrm{mM}$ for $30 \mathrm{~min}$ ) (mean $\pm \mathrm{SD}$ and $\mathbf{n}=10)$ ). ${ }^{\text {a }} \mathbf{p}<0.001 \mathrm{vs}$ control, ${ }^{\mathrm{b}} \mathrm{p}<0.001$ vs $\mathrm{BVC}$ group, ${ }^{\mathrm{c}} \mathrm{p}<0.001$ vs $\mathrm{BVC}+$ Se group and ${ }^{\mathrm{d}} \mathrm{p}<0.001$ vs Se group.

BVC: Bevacizumab group, BVC+CAPZ: Bevacizumab + capsazepine group, BVC+Se: Bevacizumab + Selenium group, BVC+Se+CAPZ: Bevacizumab + Selenium + capsazepine group, Se: Selenium group, Se+CAPZ: Selenium + capsazepine group. 

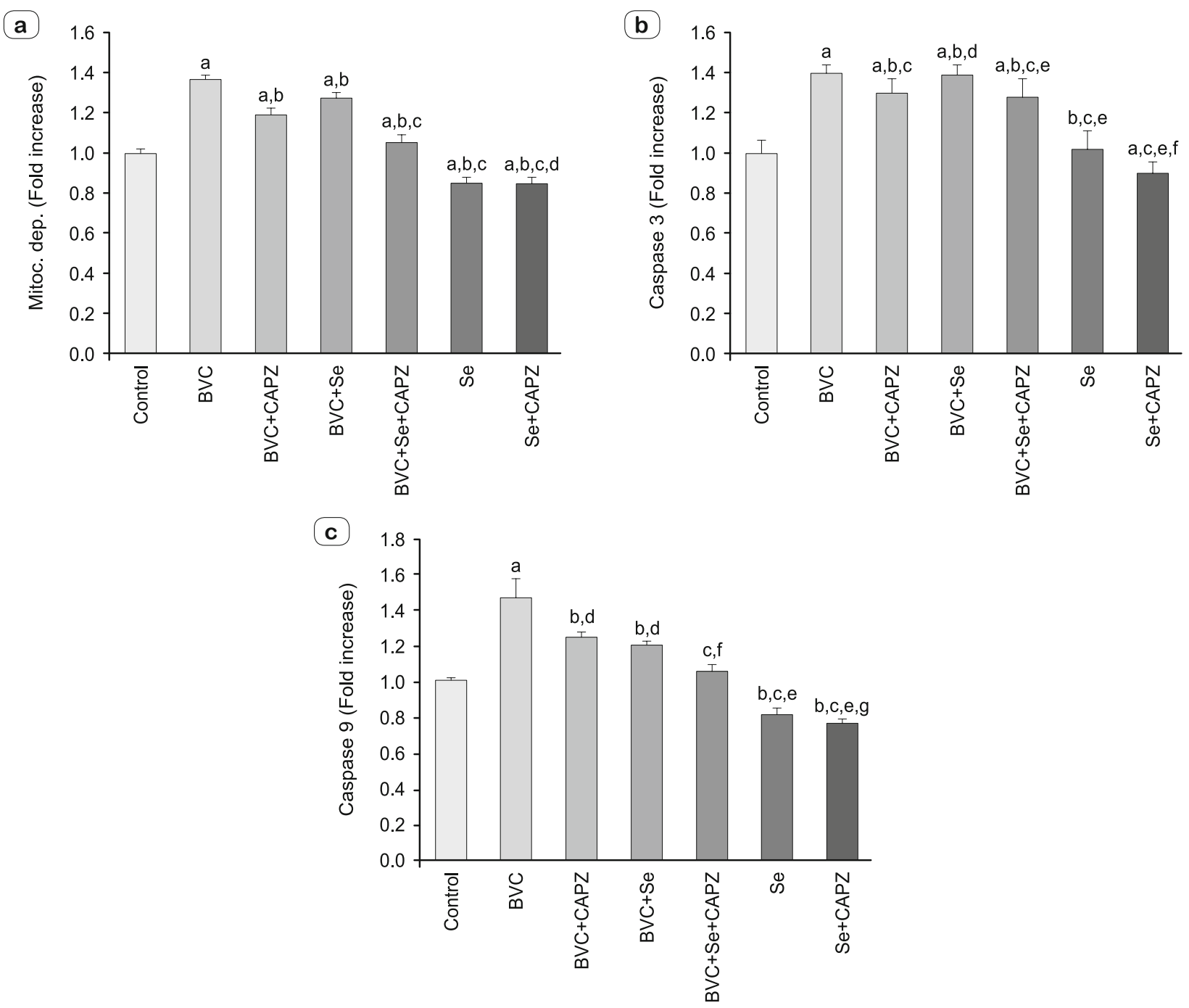

Fig. 4a, b, c. The effect of bevacizumab (1 microgram, $24 \mathrm{hrs)}$ and selenium (1 $\mu \mathrm{M}, 24 \mathrm{hrs})$ on mitochondrial depolarization levels, caspase 3 levels, caspase 9 levels in the cardiomyocytes. The cells were stimulated by capsaicin (CPSN $0.1 \mathrm{mM}$ for 10 min) and the cells in the capsazepine groups were inhibited by capsazepine (CAPZ $0.1 \mathrm{mM}$ for $30 \mathrm{~min})\left(\right.$ mean $\pm \mathrm{SD}$ and $\mathrm{n}=10$ )). a) a ${ }^{\mathrm{p}}<0.001 \mathrm{vs}$ control, ${ }^{\mathrm{b}} \mathrm{p}<0.001 \mathrm{vs} \mathrm{BVC}$ group, ${ }^{\mathrm{c}} \mathrm{p}<0.001$ vs BVC+Se group and ${ }^{\mathrm{d}} \mathrm{p}<0.05$ vs Se group. $\left.\mathrm{b}\right)^{\mathrm{a}} \mathrm{p}<0.001$ and ${ }^{\mathrm{b}} \mathrm{p}<0.05$ vs control group, ${ }^{\mathrm{c}} \mathrm{p}<0.001$ and ${ }^{\mathrm{d}} \mathrm{p}<0.05 \mathrm{vs} \mathrm{BVC}$ group, ${ }^{\mathrm{e}} \mathrm{p}<0.001$ vs BVC+Se group and ${ }^{\mathrm{f}} \mathrm{p}<0.05$ vs Se group. $\left.\mathrm{c}\right)^{\mathrm{a}} \mathrm{p}<0.001$ and ${ }^{\mathrm{b}} \mathrm{p}<0.05$ vs control group, ${ }^{\mathrm{c}} \mathbf{p}<0.001$ and ${ }^{\mathrm{d}} \mathrm{p}<0.05$ vs $\mathrm{BVC}$ group, ${ }^{\mathrm{e}} \mathbf{p}<\mathbf{0 . 0 0 1}$ and ${ }^{\mathrm{f}} \mathrm{p}<\mathbf{0 . 0 5}$ vs BVC+Se group and ${ }^{\mathrm{g}} \mathrm{p}<\mathbf{0 . 0 5}$ vs Se group. BVC: Bevacizumab group, BVC+CAPZ: Bevacizumab + capsazepine group, BVC+Se: Bevacizumab + Selenium group, BVC+Se+CAPZ: Bevacizumab + Selenium + capsazepine group, Se: Selenium group, Se+CAPZ: Selenium + capsazepine group.

Effects of bevacizumab and selenium on caspase 3-9 activities, mitochondrial depolarization levels and cell viability (MTT) values in cardiomyocytes

Levels of mitochondrial membrane depolarization, caspase 3-9 activities of groups are shown in Figure 4a, b, c respectively. It has been shown that caspase 3-9 activities had an important role in the mitochondrial apoptotic pathways. Also, they are associated with mitochondrial cytochrome $\mathrm{c}$ releasing during the apoptotic cascade.

We showed MTT values of the groups in Figure 5. The cell viability values were lower in the bevacizumab group than in the control $(p<0.001)$. The values were higher in the bevacizumab
+ capsazepine $(\mathrm{p}<0.001)$ and bevacizumab + selenium + capsazepine $(\mathrm{p}<0.001)$ groups than in the bevacizumab group.

\section{Discussion}

Bevacizumab; a recombinant humanized monoclonal antibody, blocks vessel proliferation and inhibits tumor growth by binding vascular endothelial growth factor (29). It is approved and widely used for treatment of different kinds of tumors $(30,31)$.

Bevacizumab is associated with adverse effects including a congestive heart failure. In a meta-analysis by Qi et al; it has been reported that it was associated with an increased risk of signifi- 


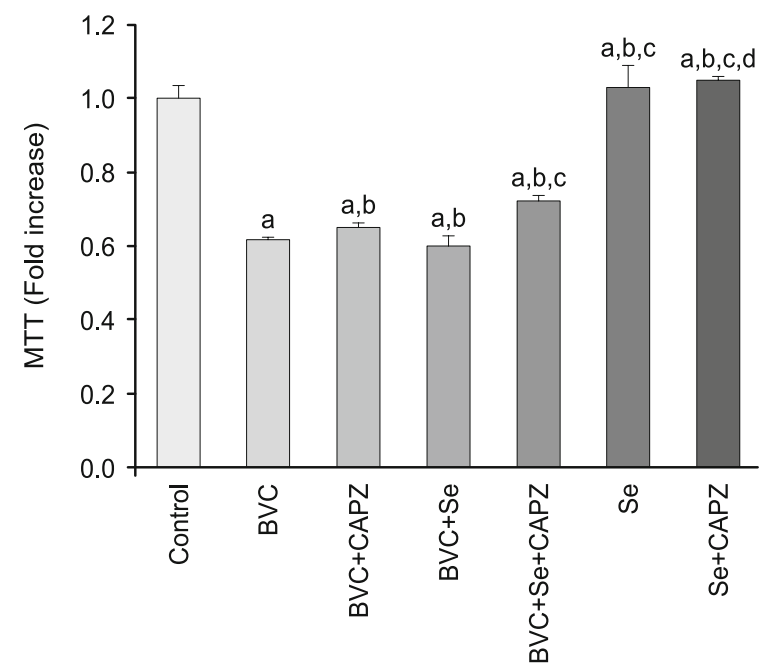

Fig. 5. The effect of bevacizumab ( 1 microgram, $24 \mathrm{hrs})$ and selenium $(1 \mu \mathrm{M}, 24 \mathrm{hrs})$ on MTT levels in the cardiomyocytes. The cells were stimulated by capsaicin (CPSN $0.1 \mathrm{mM}$ for $10 \mathrm{~min}$ ), but they were inhibited by capsazepine (CAPZ $0.1 \mathrm{mM}$ for $30 \mathrm{~min}$ ). (mean \pm SD and $\mathrm{n}=10$ ). ${ }^{\mathrm{a}} \mathbf{p}<\mathbf{0 . 0 0 1}$ vs control, ${ }^{\mathrm{b}} \mathbf{p}<\mathbf{0 . 0 0 1}$ vs $\mathrm{BVC}$ group, ${ }^{\mathrm{c}} \mathbf{p}<\mathbf{0 . 0 0 1}$ vs BVC+Se group and ${ }^{\mathrm{d}} \mathrm{p}<0.001$ vs Se group. BVC: Bevacizumab group, BVC+CAPZ: Bevacizumab + capsazepine group, BVC+Se: Bevacizumab + Selenium group, $\mathrm{BVC}+\mathrm{Se}+\mathrm{CAPZ}$ : Bevacizumab $+\mathrm{Se}-$ lenium + capsazepine group, Se: Selenium group, $\mathrm{Se}+\mathrm{CAPZ}$ : Selenium + capsazepine group.

cant heart failure (17). Choueiri et al, reported that bevacizumab increased the risk of serious systolic heart failure in patients with metastatic breast cancer (16). The important role of the VEGF pathway in myocardial contractile function has been shown before. Also, it is suggested that blocking VEGF pathway could be associated with reverse cardiac remodeling and development of heart failure (32). Besides these data; the molecular mechanism of cardiotoxicity caused by bevacizumab is not clearly understood. It has been demonstrated that chemotherapy induced cardiotoxicity is associated with the formation of reactive oxygen species (15). Also, widely used anticancer drugs including bevacizumab could cause drug induced mitochondrial dysfunction and cardiotoxicity (33). Mitochondria plays a major role in cell apoptosis. Santulli et al; demonstrated that excessive load of mitochondrial calcium was the main determinant in heart failure. They showed that intracellular calcium overload caused a mitochondrial dysfunction and contributed to a decreased left ventricular ejection fraction after an acute myocardial infarction (34). It has been shown that there was a close relationship between the heart failure and oxidative stress. Reactive oxygen species induced changes in heart failure, including myocardial hypertrophy, fibrosis and apoptosis (35). In a study by Yazici et al; bevacizumab increased the intracellular calcium level and caused a profound increase of ROS and apoptosis levels in osteoblast -like cell line. Authors concluded that antioxidant therapy could regulate apoptosis and calcium entry via TRPV1 channels in the cancer cell lines (18).

In our study, we observed that TRPV1 channels were present in cardiomyocytes and they were stimulated by capsaicin, whereas were blocked by capsazepine, respectively. In addition, we found that bevacizumab increased oxidative stress, calcium influx and apoptosis in cardiomyocytes. However, bevacizumab induced increase in apoptosis, caspase 3 - 9 and intracellular ROS production in the cells was decreased by selenium treatment.

Transient receptor potential family are unique ion channels, which mediate the influx of cations into cells in response to several stimuli. Also, they are primary targets for different drugs. It has been demonstrated that TRP channels influence cell survival rates as well as cell death (36). Transient receptor channels can be divided into seven groups, as TRP-C (canonical), TRP-V (vanilloid), TRP-M (melastatin), TRP-P (polycystin), TRPM-L (mucolipin), TRP-A (ankyrin) and TRP-N (NO mechanotransducer potential C) (37). Data of several studies showed that TRP channels had a crucial role in physiological as well as pathophysiological activities. Some channels are activated by intracellular calcium overload whereas others are constitutively open $(38,39)$. Calcium has an important role as a second messenger in cardiac function including cardiac energy homeostasis and cell death. Transient receptor potential (TRP) proteins are responsible for $\mathrm{Na}^{+}$and $\mathrm{Ca}^{2+}$ conducting channels, which cause changes in the $\mathrm{Ca}^{2+}$ homeostasis and mediate longer lasting modulation of $\mathrm{Ca}^{2+}$ levels $(40,41)$. TRPV1, a member of vanilloid TRP family, is a homotetrameric non -selective cation channel, which can be activated by intracellular and extracellular stimuli such as: temperature $>42{ }^{\circ} \mathrm{C}$, osmolarity, low $\mathrm{pH}$ or capsaicin $(42,43)$. Capsazepine is a competitive antagonist of capsaicin and it specifically blocks the TRPV1 channel (44). It has been shown that TRPV1 channels are found in the ventricles of heart and have important roles in modulating cardiovascular diseases including congestive heart failure $(10,45,46)$. In previous studies, it has been reported that activation of TRPV1 channels may aggravate congestive heart failure $(47,48)$. Horton et al, showed that blockade of TRPV1 channels had a protective effect in tissue remodeling and apoptotic changes in congestive heart failure (49). Despite the significance of oxidative stress and antioxidant therapy in chemotherapy induced cardiotoxicity, its role in TRPV1 channel modulation has not been evaluated before. Understanding the molecular mechanisms of chemotherapy induced cardiotoxicity is necessary to improve effective preventive strategies.

To the best of our knowledge, there is no report that examines the effect of using a combination of bevacizumab and selenium on apoptosis, oxidative stress and intracellular calcium increase via TRPV1 channels in cardiomyocytes. In the current study, we also observed that selenium suppressed mitochondrial membrane depolarization levels and had protective effects on the rate of programmed cell death as indicated by caspase 3 and 9 values. Cui et al, demonstrated that selenium deficiency increased the reactive oxygen species levels in myocardium and myocardial injury was apparent in selenium deficient group compared to the control (50). Selenium is an essential trace element and has critical biological functions as a co-factor in antioxidant enzymes such as glutathione peroxidase. In selenium deficiency, an accumulation of lipid peroxidation products in heart may propagate cell membrane damage and lead to an uncontrolled calcium ion accumulation into the cell. In a study by Demirci et al, authors showed that se- 
lenium treatment might have beneficial effects in oxidative stress, inflammation and apoptosis (51). Also, it is known that selenium has cardioprotective effects against toxic elements, xenobiotics and viral infections (19).

In conclusion, cardiotoxicity induced by bevacizumab is consistent with elevated levels of apoptosis, oxidative stress and increased intracellular calcium. Since no reliable and effective treatment in chemotherapy induced cardiotoxicity is available, having a good understanding of underlying pathophysiological mechanism became more important in addition to monitoring of side effects.

\section{Study limitations}

First of all, we did not evaluate concentration response to distinguish the effects of different toxic levels of bevacizumab on the molecular mechanism studied in the present study. Also, we could not be able to perform electrophysiological study and evaluate whether bevacizumab administration changes the expression of TRPV1 channels in cardiomyocytes.

\section{References}

1. Görlach A, Bertram K, Hudecova S, Krizanova O. Calcium and ROS: A mutual interplay. Redox Biol 2015; 6: 260-271.

2. Berridge MJ, Bootman MD, Roderick HL. Calcium signalling: dynamics, homeostasis and remodelling. Nat Rev Mol Cell Biol 2003; 4 : $517-529$.

3. Flemming NB, Gallo LA, Forbes JM. Mitochondrial Dysfunction and Signaling in Diabetic Kidney Disease: Oxidative Stress and Beyond. Semin Nephrol 2018; 38: 101-110.

4. Gordeeva AV, Zvyagilskaya RA, Labas YA. Cross-talk between reactive oxygen species and calcium in living cells. Biochemistry (Mosc) 2003; 68: 1077-1080.

5. Sakalli Cetin E, Naziroglu M, Cig B, Ovey IS, Aslan Koşar P. Selenium potentiates the anticancer effect of cisplatin against oxidative stress and calcium ion signaling-induced intracellular toxicity in MCF-7 breast cancer cells: involvement of the TRPV1 channel. J Recept Signal Transduct Res 2017; 37: 84-93.

6. Pecze L, Blum W, Henzi T, Schwaller B. Endogenous TRPV1 stimulation leads to the activation of the inositol phospholipid pathway necessary for sustained $\mathrm{Ca}^{+2}$ oscillations. Biochim Biophys Acta 2016; 1863 : 2905-2915.

7. Gao F, Liang Y, Wang X et al. TRPV1 Activation Attenuates High-Salt Diet-Induced Cardiac Hypertrophy and Fibrosis through PPAR- $\delta$ Upregulation. PPAR Res 2014; 2014: 491963.

8. Li BH, Yin YW, Liu Y et al. TRPV1 activation impedes foam cell formation by inducing autophagy in oxLDL-treated vascular smooth muscle cells. Cell Death Dis 2014; 5: e1182.

9. Xiong S, Wang P, Ma L et al. Ameliorating Endothelial Mitochondrial Dysfunction Restores Coronary Function via Transient Receptor Potential Vanilloid 1-Mediated Protein Kinase A/Uncoupling Protein 2 Pathway. Hypertension 2016; 67: 451-460.

10. Lang H, Li Q, Yu H et al. Activation of TRPV1 attenuates high saltinduced cardiac hypertrophy through improvement of mitochondrial function. Br J Pharmacol 2015; 172: 5548-5558.
11. Hassanpour SH, Dehghani MA, Karami SZ. Study of respiratory chain dysfunction in heart disease. J Cardiovasc Thorac Res 2018; 10 : $1-13$.

12. Nian M, Lee $\mathbf{P}$, Khaper $\mathbf{N}$, Liu $\mathbf{P}$. Inflammatory cytokines and postmyocardial infarction remodeling. Circ Res 2004; 94: 1543-1553.

13. Crouzin N, Ferreira MC, Cohen-Solal C, Barbanel G, Guiramand J, Vignes M. Neuroprotection induced by vitamin $E$ against oxidative stress in hippocampal neurons: involvement of TRPV1 channels. Mol Nutr Food Res 2010; 54: 496-505.

14. Kosar PA, Naziroglu M, Ovey IS, Cig B. Synergic Effects of Doxorubicin and Melatonin on Apoptosis and Mitochondrial Oxidative Stress in MCF-7 Breast Cancer Cells: Involvement of TRPV1 Channels. J Membr Biol 2016; 249: 129-140.

15. Angsutararux $P$, Luanpitpong $S$, Issaragrisil S. Chemotherapy-induced Cardiotoxicity: Overview of the Roles of Oxidative Stress. Oxid Med Cell Longev 2015; 2015: 795602.

16. Choueiri TK, Mayer EL, Je $Y$ et al. Congestive heart failure risk in patients with breast cancer treated with bevacizumab. J Clin Oncol 2011; 29: 632-638.

17. Qi WX, Fu S, Zhang Q, Guo XM. Bevacizumab increases the risk of severe congestive heart failure in cancer patients: an up to date metaanalysis with a focus on different subgroups. Clin Drug Investig 2014; 34: 681-690.

18. Yazici T, KoCer G, Naziroglu M, Ovey IS, Öz A. Zoledronic Acid, Bevacizumab and Dexamethasone-induced Apoptosis, Mitochondrial Oxidative Stress, and Calcium Signaling Are Decreased in Human Osteoblastlike Cell Line by Selenium Treatment. Biol Trace Elem Res 2017. doi: 10.1007/s12011-017-1187-8.

19. Gunes S, Sahinturk V, Karasati P, Sahin IK, Ayhanci A. Cardioprotective Effect of Selenium Against Cyclophosphamide-induced Cardiotoxicity in Rats. Biol Trace Elem Res 2017; 177: 107-114.

20. Uguz AC, Naziroglu M, Espino J et al. Selenium modulates oxidative stress-induced cell apoptosis in human myeloid HL-60 cells through regulation of calcium release and caspase-3 and -9 cactivities. J Membr Biol 2009; 232: 15-23.

21. Martinez NA, Ayala AM, Martinez M, Martinez-Rivera FJ, Miranda JD, Silva WI. Caveolin-1 Regulates the P2Y2 Receptor Signaling in Human 1321N1 Astrocytoma Cells. J Biol Chem 2016; 291: 12208-12222.

22. Espino J, Pariente JA, Rodríguez AB. Role of melatonin on diabetesrelated metabolic disorders. World J Diabetes 2011; 2: 82-91.

23. Özdemir ÜS, Naziroglu M, Şenol N, Ghazizadeh V. Hypericum perforatum attenuates spinal cord injury-induced oxidative stress and apoptosis in the dorsal root ganglion of rats: involvement of TRPM2 and TRPV1 channels. Mol Neurobiol 2015; 23: 1-12.

24. Espino J, Bejarano I, Redondo PC et al. Melatonin reduces apoptosis induced by calcium signaling in human leukocytes: Evidence for the involvement of mitochondria and Bax activation. J Membr Biol 2010; 233: $105-118$.

25. Bejarano I, Redondo PC, Espino $\mathbf{J}$ et al. Melatonin induces mitochondrial-mediated apoptosis in human myeloid HL-60 cells. J Pineal Res 2009; 46: 392-400.

26. Öz A, Celik Ö. Curcumin inhibits oxidative stress-induced TRPM2 channel activation, calcium ion entry and apoptosis values in SH-SY5Y neuroblastoma cells: Involvement of transfection procedure. Mol Membr Biol 2016; 33: 76-88. 
$131-138$

27. Uguz AC, Cig B, Espino J et al. Melatonin potentiates chemotherapyinduced cytotoxicity and apoptosis in rat pancreatic tumor cells. J Pineal Res 2012; 53: 91-98.

28. Övey IS, Naziroglu M. Homocysteine and cytosolic GSH depletion induce apoptosis and oxidative toxicity through cytosolic calcium overload in the hippocampus of aged mice: involvement of TRPM2 and TRPV1 channels. Neuroscience 2015; 284: 225-233.

29. Ho QT, Kuo CJ. Vascular endothelial growth factor: biology and therapeutic applications. Int J Biochem Cell Biol 2007; 39: 1349-1357.

30. Hurwitz H, Fehrenbacher L, Novotny $W$ et al. Bevacizumab plus irinotecan, fluorouracil, and leucovorin for metastatic colorectal cancer. N Engl J Med 2004; 350: 2335-2342.

31. Miller KD, Chap LI, Holmes FA et al. Randomized phase III trial of capecitabine compared with bevacizumab plus capecitabine in patients with previously treated metastatic breast cancer. J Clin Oncol 2005; 23: 792-799.

32. Giordano FJ, Gerber HP, Williams SP et al. A cardiac myocyte vascular endothelial growth factor paracrine pathway is required to maintain cardiac function. Proc Natl Acad Sci USA 2001; 98: 5780-5785.

33. Varga ZV, Ferdinandy P, Liaudet L, Pacher P. Drug-induced mitochondrial dysfunction and cardiotoxicity. Am J Physiol Heart Circ Physiol 2015; 309: H1453-1467.

34. Santulli G, Xie W, Reiken SR, Marks AR. Mitochondrial calcium overload is a key determinant in heart failure. Proc Natl Acad Sci USA 2015; 112: 11389-11394

35. Hafstad AD, Nabeebaccus AA, Shah AM. Novel aspects of ROS signaling in heart failure. Basic Res Cardiol 2013; 108: 359.

36. Fliniaux I, Germain E, Farfariello V, Prevarskaya N. TRPs and $\mathrm{Ca}^{2+}$ in cell death and survival. Cell Calcium 2018; 69: 4-18.

37. Smani T, Shapovalov G, Skryma R, Prevarskaya N, Rosado JA. Functional and physiopathological implications of TRP channels. Biochim Biophys Acta 2015; 1853: 1772-1782.

38. Venkatachalam K, Montell C. TRP channels. Annu Rev Biochem 2007; 76: 387-417.

39. Zheng J. Molecular Mechanism of TRP Channels. Compr Physiol 2013; 3: 221-342.
40. Flockerzi V, Nilius B. TRPs: truly remarkable proteins. Handb Exp Pharmacol 2014; 222: 1-12.

41. Bers DM. Calcium cycling and signaling in cardiac myocytes. Annu Rev Physiol 2008; 70: 23-49.

42. Nishihara E, Hiyama TY, Noda M. Osmosensitivity of transient receptor potential vanilloid 1 is synergistically enhanced by distinct activating stimuli such as temperature and protons. PLoS One 2011; 6: e22246.

43. Caterina MJ, Schumacher MA, Tominaga M, Rosen TA, Levine JD, Julius D. The capsaicin receptor: a heat-activated ion channel in the pain pathway. Nature 1997; 389: 816-824.

44. Van den Worm E, de Vries A, Nijkamp FP, Engels F. Capsazepine, a vanilloid receptor antagonist, inhibits allergen-induced tracheal contraction. Eur J Pharmacol 2005; 518: 77-78.

45. Li L, Wang F, Wei $X$ et al. Transient receptor potential vanilloid 1 activation by dietary capsaicin promotes urinary sodium excretion by inhibiting epithelial sodium channel $\alpha$ subunit-mediated sodium reabsorption. Hypertension 2014; 64: 397-404.

46. Randhawa PK, Jaggi AS. TRPV1 channels in cardiovascular system: A double edged sword? Int J Cardiol 2017; 228: 103-113.

47. Buckley CL, Stokes AJ. Mice lacking functional TRPV1 are protected from pressure overload cardiac hypertrophy. Channels (Austin) 2011; 5: 367-374.

48. Thilo F, Liu Y, Schulz $\mathbf{N}$ et al. Increased transient receptor potential vanilloid type 1 (TRPV1) channel expression in hypertrophic heart. Biochem Biophys Res Commun 2010; 401: 98-103.

49. Horton JS, Buckley CL, Stokes AJ. Successful TRPV1 antagonist treatment for cardiac hypertrophy and heart failure in mice. Channels (Austin) 2013; 7: 17-22.

50. Cui J, Zhong R, Chu $\mathbf{E}$ et al. Correlation between oxidative stress and L-type calcium channel expression in the ventricular myocardia of selenium-deficient mice. J Int Med Res 2012; 40: 1677-1687.

51. Demirci K, Naziroglu M, Övey IS, Balaban H. Selenium attenuates apoptosis, inflammation and oxidative stress in the blood and brain of aged rats with scopolamine-induced dementia. Metab Brain Dis 2017; 32: $321-329$. 